\title{
Genetic diversity in population of largemouth bronze gudgeon (Coreius guichenoti Sauvage et Dabry) from Yangtze River determined by microsatellite DNA analysis
}

\author{
Futie Zhang and Deqing Tan* \\ Key Laboratory of Aquatic Biodiversity and Conservation of Chinese Academy of Sciences, \\ Institute of Hydrobiology, Chinese Academy of Sciences, Wuhan 430072, China
}

(Received 25 August 2010, accepted 23 November 2010)

\begin{abstract}
Largemouth bronze gudgeon (Coreius guichenoti Sauvage et Dabry 1874), one of the endemic fish species in the upper reaches of the Yangtze River in China, is a benthic and potamodromous fish that is typically found in rivers with torrential flow. Three dams in the Yangtze River, Ertan Dam, Three Gorges Dam and Gezhouba Dam, may have had vital impacts on the habitat and spawning behaviors of largemouth bronze gudgeon, and could ultimately threaten the survival of this fish. We studied the population genetic diversity of $C$. guichenoti samples collected at seven sites (JH, GLP, BX, HJ, MD, SDP and XB) within the Yangtze River and one of its tributaries, the Yalong River. Genetic diversity patterns were determined by analyzing genetic data from 11 polymorphic microsatellite loci. A high genetic diversity among these largemouth bronze gudgeon populations was indicated by the number of microsatellite alleles $(A)$ and the expected heterozygosity $(H E)$. No significant population variation occurred among GLP, BX, HJ and MD populations, but dramatic population differentiation was observed among $\mathrm{JH}$ and $\mathrm{XB}$, two dam-blocked populations, versus other populations. Tests for bottlenecks did not indicate recent dramatic population declines and concurrent losses of genetic diversity in any largemouth bronze gudgeon populations. To the contrary, we found that dams accelerated the population differentiation of this fish.
\end{abstract}

Key words: genetic differentiation, genetic diversity, largemouth bronze gudgeon (Coreius guichenoti Sauvage et Dabry), microsatellite

\section{INTRODUCTION}

Largemouth bronze gudgeon (Coreius guichenoti Sauvage et Dabry 1874), belonging to Cyprinidae in the Cypriniformes, is one of the endemic fishes and an important economic fish in the upper reaches of Yangtze River in China (Chen et al., 2002; Duan et al., 2002; Fu et al., 2003; Yu et al., 2005). Due to environmental pollutions, overexploitation and construction of electrical projects, the number of largemouth bronze gudgeon in the Yangtze River has declined significantly (Duan et al., 2002). Largemouth bronze gudgeon is a benthic and potamodromous fish that is typically found in rivers with torrential flow. They always live in schools and produce pelagic eggs in flows from March to June every year. Its spawning fields lie mainly in the middle and lower reaches of the Jinsha River (another name for the upper reaches of

Edited by Hidenori Tachida

* Corresponding author. E-mail: dqtan@ihb.ac.cn
Yangtze River above the Yibin City segment) and the lower reaches of the Yalong River, a tributary of Jinsha River (Institute of Hydrobiology, 1976; The Changjiang River fisheries investigation team of Sichuan Province, 1979; Liu et al., 1990). The eggs and larval fishes drift downstream and some larvae reach the middle reaches of Yangtze River downstream of Yichang City. After about three years, the adults return to the spawning fields and start a new cycle of reproduction.

Three dams lacking fishways have now been constructed within the habitat and spawning fields of largemouth bronze gudgeon along the Yangtze River and the Yalong River. Ertan Dam, constructed from 1991 to 2000 , is at the down reaches of Yalong River. It separates the spawning field of Yalong River from other spawning fields and blocks the migratory mature largemouth bronze gudgeon returning to this spawning field. Gezhouba Dam, built from 1974 to 1988, is in the middle segment of Yangtze River in Yichang City. Three Gorges Dam, constructed from 1994 to 2006, is also in 
Yichang City, just 38 kilometers upstream of the Gezhouba Dam. These three hydro-projects have dramatically changed the hydrological conditions in the upper and middle reaches of the Yangtze River, which may have also changed the environments for habitat and spawning fields of largemouth bronze gudgeon. Such changes could ultimately threaten the survival of this fish. Based on available biological data on the endemic fishes in the upper reaches of Yangtze River and an artificial neural network model, Park et al. (2004) deduced that six endemic fishes, including largemouth bronze gudgeon, are in great danger of extinction after the full deposit of the Three Gorges Dam.

However, little is known about the genetic diversity in the natural population of largemouth bronze gudgeon. Until recently, its microsatellite DNA makers have been isolated (Liao et al., 2007; Xu et al., 2007), and genetic diversity of populations in the Yibin section of Yangtze River and other four sites from Yibin (in Yibin section) to Fuling (in Chongqing section) of Yangtze River has been analyzed (Xu et al., 2007; Yuan et al., 2008, Fig. 1). High genetic diversity was observed in Yibin population but no population differentiation appeared from Yibin to Fuling
(Xu et al., 2007; Yuan et al., 2008).

In this study, we sought to elucidate the genetic diversity of the whole natural population of the largemouth bronze gudgeon by examining the patterns of genetic diversity and differentiation among population samples of C. guichenoti, as determined by genetic data from 11 polymorphic microsatellite loci. Samples were collected from seven sites within the Yangtze River and one of its tributaries (Fig. 1, Table 1). Potential effects of the hydroprojects that lie among the habitat and spawning fields of largemouth bronze gudgeon on genetic structure of local populations of the fish were analyzed.

\section{MATERIALS AND METHODS}

Sampling During the spring (Apr-Jun) and fall (OctNov) of 2007, largemouth bronze gudgeon fish was sampled at seven sites along the Yangtze River and one of its tributaries (Fig. 1, Table 1). Depending on watercourse size, largemouth bronze gudgeon were collected using gill nets or dipnets. After photos of the fish were taken, fin clips were collected for genetic analysis and the fish body

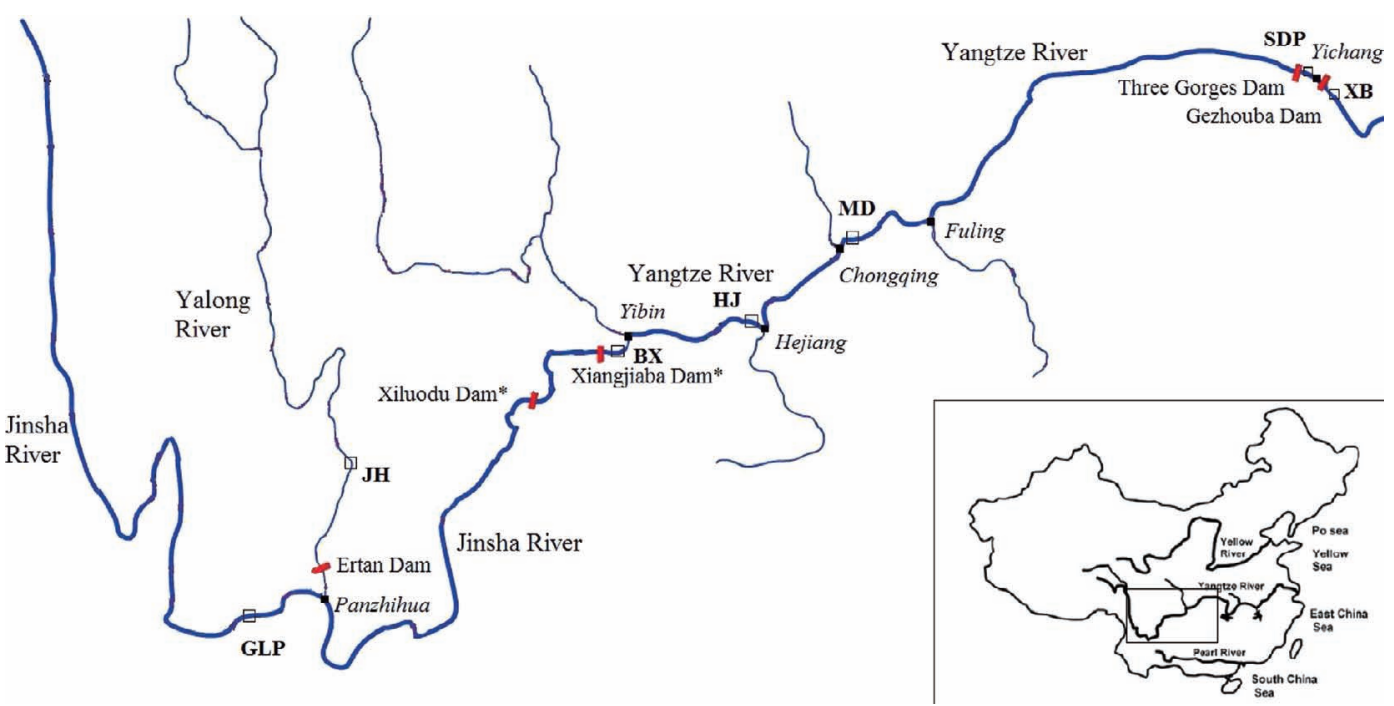

Fig 1. Map of the Yangtze River and its tributaries showing the approximate sampling locations (by hollow squares) and dams (by red rectangles, with those under construction marked by a superscript asterisk).

Table 1. Description of sites and samples

\begin{tabular}{cccc}
\hline \hline Site & River & Sample size & Abbreviation \\
\hline Jinhe town, Yanyuan county, Sichuan Prov. & Yalong River & 34 & JH \\
Geliping town, Panzhihua city, Sichuan Prov. & Jinsha River & 24 & GLP \\
Baixi town, Yibin city, Sichuan Prov. & Jinsha River & 33 & BX \\
Hejiang town, Hejiang county, Sichuan Prov. & Yangtze River & 30 & HJ \\
Mudong town, Ba'nan of Chongqing city & Yangtze River & 30 & MD \\
Sandouping town, Yiling of Yichang city, Hubei Prov. & Yangtze River & 25 & SDP \\
Xiba, Xiling of Yichang city, Hubei Prov. & Yangtze River & 42 & XB \\
\hline
\end{tabular}


length and body weight were measured before releasing them. Fin clips were stored in 95\% ethanol. Fish samplings were confirmed to be that of the right species based on the photos.

DNA extraction and microsatellite analysis Genomic DNA extraction was conducted according to the method described by Aljanabi and Martinez (1997) with some modifications: $300 \mathrm{mg}$ fin clips were lysed at $55^{\circ} \mathrm{C}$ for 6-8 hours in $2 \mathrm{ml}$ tubes with $500 \mu \mathrm{l} \mathrm{HOM}$ buffer (100 mM Tris-HCl pH 8.0, 80 mM EDTA, 0.5\% SDS w/v) and $10 \mu \mathrm{l}$ Proteinase K (Merck, $10 \mathrm{mg} / \mathrm{ml})$. Then $500 \mu \mathrm{l}$ $\mathrm{NaCl}(4.5 \mathrm{M})$ and $300 \mu \mathrm{CHCl}_{3}$ were added. Supernatants were transferred into $1.5 \mathrm{ml}$ sterile tubes. To precipitate DNA, $600 \mu \mathrm{l}$ isopropanol was added to tubes. Samples were centrifuged, and supernatant was removed and $500 \mu \mathrm{l}$ of $70 \%$ ethanol was added to remove excess salts. Ethanol was removed and DNA was resuspended in 100-200 $\mu$ l of $1 \times$ TE ( $10 \mathrm{mM}$ Tris, $1 \mathrm{mM}$ EDTA). DNA was visually inspected for quality and quantity on $0.8 \%$ agarose gels.

11 microsatellite DNA loci were amplified using the polymerase chain reaction (PCR) procedure. Nine microsatellite primers of $C$. guichenoti were synthesized according to the submitted sequences on Genbank (Liao et al., 2007). Two microsatellite primers of $C$. heterodon were from Liao et al. (2006). PCR was performed in $20 \mu \mathrm{l}$ reactions consisting of $1 \times$ PCR buffer, $1.0-3.0 \mathrm{mM} \mathrm{MgCl}$, $0.1 \mathrm{mM}$ dNTPs (Amresco), $0.2 \mu \mathrm{M}$ primers, 0.3 units Taq DNA polymerase (Fermentas) and about $20 \mathrm{ng}$ genomic DNA. The basic thermocycling program was $94^{\circ} \mathrm{C}$ for $4 \mathrm{~min}$; then 35 cycles at $94^{\circ} \mathrm{C}$ for $30 \mathrm{~s}, \mathrm{~N}^{\circ} \mathrm{C}(\mathrm{N}$ is the annealing temperature, which is from 50 to 60 , as suggested by Liao et al. 2006,2007 ) for $40-60 \mathrm{~s}$, and $72^{\circ} \mathrm{C}$ for $60 \mathrm{~s}$, with a final step at $72^{\circ} \mathrm{C}$ for $10 \mathrm{~min}$. PCR products were electrophoresed in nondenaturing $8 \%$ polyacrylamide gels (Ais: Bis = 29: 1) on Sequi-Gen GT system (Bio-Rad).

The gels were silver-stained according to the methods described by Panaud et al. (1996). The allele sizes were obtained by manually comparing the alleles' size with the pBR322 DNA/Msp I and PUC18 DNA/MspI markers (Tiangen). Only intensely stained unambiguous, clear bands were counted. Genotypes were checked for scoring errors attributable to stutter-products, large allele drop-out, or null alleles, using MICRO-CHECKER v2.2.3 (Van Oosterhout et al., 2004).

Data analysis Number of alleles $(A)$, expected and observed heterozygosity ( $H E$ and $H O$, respectively) and genetic distances were compiled using Popgene software v1.32 (Yeh et al., 1997). Standardized allelic richness $(A r)$ and F-statistics $\left(F_{S T}\right.$ and $\left.F_{I S}\right)$ were estimated using Fstat software v2.9.3.2 (Goudet, 2001). F-statistics were also computed by Arlequin software v3.1 (Excoffier et al., 2005). A Bonferroni correction was used for multiple testing (Rice, 1989). Bottleneck software v1.2 (Cornuet and Luikart, 1996) was performed to test whether the fish populations have experienced great reductions recently.

\section{RESULTS}

Population genetic diversity Microsatellite DNAs of 218 fishes from seven locations were analyzed, in which all 11 microsatellite loci (CG08, CG09, CG14, CG15, CG18, CG19, CG23, CG29, CG30, CH15 and CH20) were found to be polymorphic, with the number of alleles per locus ranging from 5 to 19 (mean $=11.9$ ). Allelic richness ranged from 3.512 to 12.283 . The observed heterozygosity $(H O)$ was from 0.2333 to 1 (mean = 0.3382-1.0000), while the expected heterozygosity $(H E)$ ranged from 0.2469 to 0.9333 (mean $=0.4123-0.9301)$ (Table 2). Null alleles were checked by MICROCHECKER. There was no evidence for large allele dropout or scoring error caused by stuttering through the 11 polymorphic loci. The locus $\mathrm{CH} 20$, however, had one null allele with the predicted frequency of $0.1846-0.2424$.

Population genetic differentiation Pairwise comparisons among populations indicated that population genetic distance ranged from 0.0904 to 0.2836 (Table 3 ). The similarity between $\mathrm{JH}$ and HJ populations was the lowest, while HJ population was the one most similar to the MD population with the least genetic distance.

F-statistics were computed by both Fstat and Arlequin softwares, and no conflicting results appeared. The inbreeding coefficient $\left(F_{I S}\right)$ values in $\mathrm{CH} 20$ of each population were found to be irregularly high. The mean value of $F_{I S}$ among seven populations ranged from 0.0687 (GLP population) to 0.0117 (SDP population) ( $F_{I S}$ from -0.0820 to -0.0416 excluding $\mathrm{CH} 20$, all $p>0.05$ ) (Table 2). No local populations were in departure from Hardy-Weinberg equilibrium (HWE) across all loci. However, in the whole population, the loci CH20 and CG19 were seen to significantly depart from $\operatorname{HWE}(p<0.05)$. So in the next analysis, CH20 locus was excluded. Analysis by the Bottleneck software did not suggest any recent dramatic reduction in the effective population size of all native samples.

Genetic differentiations $\left(F_{S T}\right)$ at 10 polymorphic loci (except CH20) among all populations ranged from 0.0129 $(p=0.62727$, HJ Vs MD) to 0.0466 ( $p=0.00000$, HJ Vs JH) (Table 4) as determined by pairwise comparisons. Four populations without dam blockages (GLP, BX, HJ and MD) had lower $F_{S T}$ values $\left(F_{S T}=0.0129-0.0225\right.$, all $p>0.05$ ) than dam-blocked populations (JH and XB), and no statistically significant difference was observed among $\mathrm{BX}, \mathrm{HJ}$ and MD. It is worth noting that this result is consistent with a previous study by Yuan et al (2008). JH population, an upstream population where gene inflow has been blocked by Ertan Dam for about 
Table 2. Summary statistics of genetic analysis at 11 microsatellite loci at 7 locations. Number of alleles $(A)$; Allelic richness $(A r)$; Observed heterozygosity $(H O)$; Expected heterozygosity $(H E)$; Inbreeding coefficient $\left(F_{I S}\right)$, the average $F_{I S}$ excluding CH20 of populations are given in parentheses

\begin{tabular}{|c|c|c|c|c|c|c|c|c|c|c|c|c|}
\hline \multirow[t]{2}{*}{ Population } & \multicolumn{2}{|c|}{ Microsatellite loci } & \multirow[b]{2}{*}{ CG18 } & \multirow[b]{2}{*}{ CG23 } & \multirow[b]{2}{*}{$\mathrm{CH} 15$} & \multirow[b]{2}{*}{$\mathrm{CH} 20$} & \multirow[b]{2}{*}{ CG09 } & \multirow[b]{2}{*}{ CG14 } & \multirow[b]{2}{*}{ CG19 } & \multirow[b]{2}{*}{ CG29 } & \multirow[b]{2}{*}{ CG30 } & \multirow[t]{2}{*}{ Mean } \\
\hline & CG08 & CG15 & & & & & & & & & & \\
\hline \multicolumn{13}{|l|}{ JH } \\
\hline$A$ & 9 & 14 & 9 & 7 & 13 & 16 & 8 & 9 & 4 & 15 & 6 & \\
\hline$A r$ & 7.381 & 10.278 & 8.366 & 6.177 & 9.518 & 12.190 & 7.128 & 7.937 & 3.463 & 10.474 & 5.617 & \\
\hline HO & 1.0000 & 1.0000 & 0.6471 & 1.0000 & 0.7059 & 0.4706 & 1.0000 & 1.0000 & 0.3529 & 0.8235 & 1.0000 & 0.8182 \\
\hline$H E$ & 0.8622 & 0.8999 & 0.8793 & 0.7770 & 0.8854 & 0.9333 & 0.8306 & 0.8699 & 0.3955 & 0.9074 & 0.7682 & 0.8190 \\
\hline$F_{I S}$ & -0.1627 & -0.1131 & 0.2670 & -0.2926 & 0.2052 & 0.4995 & -0.2078 & -0.1522 & 0.1091 & 0.0936 & -0.3077 & $\begin{array}{c}-0.0056 \\
(-0.0561)\end{array}$ \\
\hline \multicolumn{13}{|l|}{ GLP } \\
\hline$A$ & 8 & 8 & 8 & 7 & 9 & 11 & 7 & 8 & 4 & 10 & 6 & \\
\hline$A r$ & 7.988 & 7.914 & 7.843 & 6.840 & 8.769 & 10.680 & 6.920 & 7.846 & 4.000 & 9.686 & 5.997 & \\
\hline HO & 1.0000 & 1.0000 & 0.6923 & 1.0000 & 0.8462 & 0.8462 & 1.0000 & 1.0000 & 0.4167 & 0.7692 & 1.0000 & 0.8700 \\
\hline$H E$ & 0.8862 & 0.8677 & 0.8677 & 0.7877 & 0.8923 & 0.9015 & 0.8554 & 0.8708 & 0.3732 & 0.8831 & 0.8523 & 0.8216 \\
\hline$F_{I S}$ & -0.1346 & -0.1599 & 0.2088 & -0.2840 & 0.0538 & 0.0638 & -0.1774 & -0.1556 & -0.1225 & 0.1336 & -0.1818 & $\begin{array}{c}-0.0687 \\
(-0.0820)\end{array}$ \\
\hline \multicolumn{13}{|l|}{ BX } \\
\hline$A$ & 9 & 14 & 9 & 7 & 13 & 18 & 8 & 9 & 4 & 12 & 6 & \\
\hline$A r$ & 7.493 & 11.415 & 7.207 & 5.775 & 10.755 & 12.747 & 7.128 & 7.864 & 3.436 & 9.857 & 5.805 & \\
\hline HO & 1.0000 & 1.0000 & 0.5758 & 0.9697 & 0.7879 & 0.6364 & 1.0000 & 1.0000 & 0.3030 & 0.8788 & 1.0000 & 0.8320 \\
\hline$H E$ & 0.8438 & 0.9259 & 0.8117 & 0.7497 & 0.9184 & 0.9268 & 0.8592 & 0.8611 & 0.4047 & 0.8960 & 0.8177 & 0.8195 \\
\hline$F_{I S}$ & -0.1885 & -0.0814 & 0.2938 & -0.2995 & 0.1440 & 0.3167 & -0.1669 & -0.1643 & 0.2541 & 0.0196 & -0.2272 & $\begin{array}{c}-0.0091 \\
(-0.0416)\end{array}$ \\
\hline \multicolumn{13}{|l|}{ HJ } \\
\hline$A$ & 9 & 11 & 10 & 7 & 14 & 12 & 8 & 9 & 4 & 11 & 6 & \\
\hline$A r$ & 7.315 & 9.657 & 8.769 & 6.229 & 10.490 & 10.109 & 6.710 & 8.206 & 3.074 & 8.585 & 5.185 & \\
\hline HO & 1.0000 & 1.0000 & 0.8000 & 1.0000 & 0.8000 & 0.5333 & 0.9310 & 1.0000 & 0.2759 & 0.8333 & 1.0000 & 0.8340 \\
\hline$H E$ & 0.8102 & 0.9056 & 0.8734 & 0.7927 & 0.9090 & 0.9023 & 0.8246 & 0.8785 & 0.4483 & 0.8746 & 0.7808 & 0.8182 \\
\hline$F_{I S}$ & -0.2393 & -0.1062 & 0.0854 & -0.2673 & 0.1218 & 0.4130 & -0.1317 & -0.1328 & 0.3888 & 0.0479 & -0.2870 & $\begin{array}{c}-0.0098 \\
(-0.0520)\end{array}$ \\
\hline \multicolumn{13}{|l|}{ MD } \\
\hline$A$ & 10 & 12 & 9 & 9 & 12 & 16 & 7 & 9 & 4 & 13 & 6 & \\
\hline$A r$ & 8.369 & 9.458 & 8.542 & 7.242 & 9.611 & 11.653 & 6.655 & 7.987 & 3.227 & 9.806 & 5.079 & \\
\hline $\mathrm{HO}$ & 1.0000 & 1.0000 & 0.9333 & 1.0000 & 0.5000 & 0.7333 & 1.0000 & 1.0000 & 0.2333 & 0.8333 & 1.0000 & 0.8394 \\
\hline$H E$ & 0.8763 & 0.8797 & 0.8898 & 0.8305 & 0.8915 & 0.9209 & 0.8486 & 0.8650 & 0.2469 & 0.8780 & 0.7243 & 0.8047 \\
\hline$F_{I S}$ & -0.1440 & -0.1395 & -0.0498 & -0.2083 & 0.4434 & 0.2065 & -0.1821 & -0.1592 & 0.0558 & 0.0517 & -0.3898 & $\begin{array}{c}-0.0469 \\
(-0.0722)\end{array}$ \\
\hline \multicolumn{13}{|l|}{ SDP } \\
\hline$A$ & 9 & 12 & 10 & 10 & 11 & 13 & 8 & 9 & 5 & 11 & 6 & \\
\hline$A r$ & 8.145 & 10.804 & 9.079 & 8.686 & 9.707 & 10.605 & 6.547 & 8.312 & 4.006 & 8.704 & 4.953 & \\
\hline HO & 1.0000 & 0.9600 & 0.6364 & 1.0000 & 0.9200 & 0.3600 & 1.0000 & 1.0000 & 0.3333 & 0.8000 & 1.0000 & 0.8191 \\
\hline$H E$ & 0.8776 & 0.9224 & 0.8932 & 0.8849 & 0.9004 & 0.9053 & 0.8131 & 0.8816 & 0.4211 & 0.8384 & 0.7641 & 0.8275 \\
\hline$F_{I S}$ & -0.1429 & -0.0416 & 0.2924 & -0.1331 & -0.0222 & 0.6073 & -0.2358 & -0.1374 & 0.2120 & 0.0467 & -0.3172 & $\begin{array}{r}0.0117 \\
(-0.0479)\end{array}$ \\
\hline
\end{tabular}

XB

\begin{tabular}{lllllllllllll}
$A$ & 11 & 13 & 10 & 9 & 15 & 14 & 9 & 9 & 4 & 13 & 4 \\
\hline Continued & & & & & & &
\end{tabular}


Table 2. Continued

\begin{tabular}{lcccccccccccc}
\hline \hline$A r$ & 9.063 & 10.367 & 8.438 & 7.528 & 10.499 & 10.598 & 6.910 & 7.936 & 3.555 & 9.116 & 3.996 & \\
$H O$ & 0.9524 & 0.9286 & 0.8571 & 1.0000 & 0.8571 & 0.5476 & 0.9762 & 1.0000 & 0.4524 & 0.8810 & 1.0000 & 0.8593 \\
$H E$ & 0.8804 & 0.8962 & 0.8818 & 0.8669 & 0.9071 & 0.9091 & 0.8330 & 0.8692 & 0.5075 & 0.8741 & 0.7476 & 0.8339 \\
$F_{I S}$ & -0.0829 & -0.0366 & 0.0283 & -0.1557 & 0.0557 & 0.4005 & -0.1743 & -0.1526 & 0.1097 & -0.0080 & -0.3432 & -0.0327 \\
& & & & & & & & & & & &
\end{tabular}

All populations

\begin{tabular}{lccccccccccccc}
$A$ & 13 & 14 & 11 & 10 & 16 & 19 & 9 & 10 & 5 & 17 & 7 & \\
$A r$ & 8.846 & 10.695 & 8.810 & 8.219 & 10.976 & 12.283 & 6.937 & 8.050 & 3.512 & 9.897 & 6.492 & \\
$H O$ & 0.9903 & 0.9807 & 0.7451 & 0.9952 & 0.7681 & 0.5700 & 0.9854 & 1.0000 & 0.3382 & 0.8406 & 1.0000 & \\
$H E$ & 0.8777 & 0.9129 & 0.8826 & 0.8691 & 0.9134 & 0.9301 & 0.8476 & 0.8718 & 0.4123 & 0.8893 & 0.8387 & 0.8405 \\
$F_{I S}$ & -0.1536 & -0.0890 & 0.1461 & -0.2264 & 0.1503 & $0.3816^{*}$ & -0.1812 & -0.1508 & $0.1725^{*}$ & 0.0455 & -0.3020 & -0.0188 \\
& & & & & & & & & & & & & \\
\hline
\end{tabular}

Population significantly deviated from HWE is identified by a superscript asterisk $(p<0.05)$.

Table 3. Nei's unbiased genetic distance analyzed by Popgene software (excluding the CH20 locus)

\begin{tabular}{lccccccc}
\hline \hline & JH & GLP & BX & HJ & MD & SDP & XB \\
\hline JH & & & & & & & \\
GLP & 0.2010 & & & & & & \\
BX & 0.2019 & 0.1201 & & & & & \\
HJ & 0.2836 & 0.1681 & 0.0967 & & & & \\
MD & 0.2387 & 0.1344 & 0.0997 & 0.0904 & & & \\
SDP & 0.1504 & 0.1418 & 0.1750 & 0.1777 & 0.1783 & & \\
XB & 0.1639 & 0.1957 & 0.1880 & 0.2179 & 0.2373 & 0.1422 & \\
\hline
\end{tabular}

Table 4. Pairwise $F_{S T}$ values between 7 C. guichenoti populations compiled by Arlequin and Fstat softwares (excluding CH20). Below the diagonal, $F_{S T}$. Above the diagonal, $p$ values. Significant results are indicated in bold $(p<0.05)$

\begin{tabular}{|c|c|c|c|c|c|c|c|}
\hline & $\mathrm{H}$ & LP & $\mathrm{X}$ & $\mathrm{IJ}$ & MD & SDP & $\mathrm{XB}$ \\
\hline $\mathrm{H}$ & & & & 0.00000 & 00 & 00 & 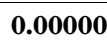 \\
\hline LP & 0.0285 & & 55 & 0.06636 & 0.27273 & 0.1 & 0.027 \\
\hline$X$ & 0.0332 & 0.0133 & & & 0.08182 & 0.1 & 0.000 \\
\hline 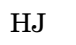 & 0.0466 & 0.02 & 0.01 & & 0.62727 & 0.0 & 0.027 \\
\hline ID & & 0 & 0150 & 0 & & 16364 & 0 \\
\hline 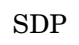 & 3 & 0 & 0.0263 & 0.0267 & 0.0 & & (5) \\
\hline $\mathrm{P}$ & 0.0258 & 0.0268 & 0.0298 & 0.0347 & 0.0402 & 0.0150 & \\
\hline
\end{tabular}

seven years, showed significantly higher $F_{S T}$ values compared to each of the four populations sampled from rivers without dam blockages (GLP, BX, HJ and MD) $\left(F_{S T}=\right.$ 0.0285-0.0466, all $p<0.01$ ). SDP population, a downstream population separated by the Three Gorges Dam for about one year from the GLP, BX, HJ and MD populations, showed insignificant variations $\left(F_{S T}=0.0153\right.$ 0.0289 , all $p>0.05$ ). However, $\mathrm{XB}$ population, the most downstream population blocked by the Three Gorges Dam for about one year and by Gezhouba Dam for about 19 years, showed significant differences in $F_{S T}$ values compared to GLP, BX, HJ and MD populations $\left(F_{S T}=0.0268\right.$ 0.0402 , all $p<0.05)$.

\section{DISCUSSION}

Genetic diversity In this study, we examined the genetic diversity of largemouth bronze gudgeon $(C$. guichenoti) fishes found at different locations along the Yangtze River by analyzing microsatellite markers. All 11 microsatellite loci were found highly polymorphic, with a mean value of 11.9 alleles $(A)$ per locus and per population. Expected heterozygosity is generally used as an indicator of genetic diversity (DeWoody and Avise, 2000), and gene diversity of 11 loci in this study was very high $(H E=0.8405)$ (Table 2). In a previous study, DeWoody and Avise (2000) compared microsatellite variation in 78 species of both freshwater and marine fishes and values of $H E=0.58$ and $A=7.1$ for freshwater fishes was observed. These values are far lower than what we obtained in this study about $C$. guichenoti, suggesting that largemouth bronze gudgeon may naturally have a higher genetic diversity. Furthermore, no declines in genetic diversity were noted in dam-blocked populations, JH, SDP and XB, when compared with other unblocked populations such as GLP, BX, HJ and MD.

In addition to affecting gene flow between different populations, dams may also reduce the genetic diversity within isolated fish populations and increase genetic differentiation among different fish populations (Yamamoto et al., 2004; Reid et al., 2008). At larger spatial scales, by restricting the movement of individuals, dams can increase genetic differentiation between previously connected or panmictic fish populations (Meldgaard et al., 2003), create upstream-downstream gradients in genetic diversity (Yamamoto et al., 2004), and disrupt the 
regional equilibrium between drift and immigration of new alleles in populations (Hutchinson and Templeton, 1999). Our analysis using the Bottleneck program did not indicate recent population declines and concurrent losses of genetic diversity in any largemouth bronze gudgeon populations (Table 2). Studies on catostomids have also reported no declines in genetic diversity between populations with a period of times isolated by dam blockage, which resulted from their relatively late age of maturity and long life-spans (Whitehead et al., 2003; Lippe et al., 2006). In the Yangtze River, largemouth bronze gudgeon fishes begin to mature at age $3-4$ and live up to more than 8 years (The Changjiang River fisheries investigation team of Sichuan Province, 1979). Therefore, it is likely that the time elapsed since the construction of Ertan Dam may not be long enough for its impact on genetic diversity of the isolated $\mathrm{JH}$ population to be seen. It is plausible that unlike fishes with shorter generation times and life spans, largemouth bronze gudgeon would be less likely to undergo rapid changes in genetic diversity resulting from population declines and short term isolation. In addition, no changes in genetic diversity were observed in the SDP or XB population either. One of the factors contributing to this lack of change may be the partial supplement of fish through Three Gorges Dam and Gezhouba Dam from upstream regions.

Genetic differentiation No heterozygote deficits were detected in any of seven populations (the negative $F_{I S}$ mean values without CH20 locus in Table 2). Interestingly, an increase of genetic differentiation was observed in some largemouth bronze gudgeon populations (Table 4). In this study, $F_{S T}$ was used instead of $R_{S T}$ because $F_{S T}$ estimates are more commonly used when fewer $(<20)$ microsatellite loci are analyzed and when populations have recently diverged (Gaggiotti et al., 1999). The JH population, without any gene inflow due to Ertan Dam for about seven years, showed significantly higher $F_{S T}$ values versus the four downstream populations GLP, BX, HJ and MD $(p<0.01)$, while XB population, the most downstream population, blocked by Three Gorges Dam for about one year and by Gezhouba Dam for about 19 years, showed slightly lower but significant $F_{S T}$ values when compared to the GLP, BX, HJ and MD populations (all $p<0.05$ ). These observations suggest that gene flow may be more influential than other factors such as drift (Hutchinson and Templeton, 1999) in genetic differentiation. Ertan Dam, Three Gorges Dam and Gezhouba Dam, all without fishways, may have reduced the chances of gene flow from upstream to downstream regions while completely blocking the opportunities of gene flow from downstream to upstream regions. SDP population, separated by the Three Gorges Dam for about one year from the upstream GLP, BX, HJ and MD populations, showed insignificant variations comprared to these four populations (all $p>$
0.05). However, the XB population, blocked by the Three Gorges Dam for about one year and by the Gezhouba Dam for about 19 years, showed significant differences in $F_{S T}$ values compared to the GLP, BX, HJ and MD populations. Our observations strongly suggest that dams do accelerate the population differentiation of this fish. Differences in isolation periods could be the main cause for the observed difference in results between SDP and XB populations.

The similarity observed between $\mathrm{HJ}$ and MD with the lowest $F_{S T}$ values (HJ Vs MD, genetic distance $=0.0904$, $F_{S T}=0.0129$ with $p=0.62727$, Tables 3 and 4) could be due to the shortest unblocked geographical distance between these two sampling sites (Fig. 1). Different pairwise $F_{S T}$ values and genetic distances were observed among the four unblocked populations (GLP, BX, HJ and $\mathrm{MD}, F_{S T}=0.0129-0.0225$, all $p>0.05$, Table 4; genetic distances $=0.0904-0.1681$, Table 3 ). These results could be explained in part by the possibility that differences in biotypes or subpopulations (for example, resident vs. migratory, or different stocks spawning at different times) of largemouth bronze gudgeon might exist (The Changjiang River fisheries investigation team of Sichuan Province, 1979). In support of this possibility, our recent investigations revealed some exceptionally young fishes of largemouth bronze gudgeon in Mudong of Chongqing between December and January. These fishes were much younger than the majority born within the normal spawning season from March to June (Unpublished data). In terms of their habitat behaviors, largemouth bronze gudgeon may be similar to fishes such as salmonids. Previous studies have documented that salmonids have a complex life history, with some populations being composed largely of migratory individuals, while others are largely non-migratory (resident) and yet others are a mixture of the two (Behnke, 1972; Hildebrand, 2003; Deiner et al., 2007).

The spawning fields of largemouth bronze gudgeon span mainly from the middle reaches of the Jinsha River to the section of the Yangtze River above Yibin city and downstream of the Yalong River. Ertan Dam has separated the Yalong spawning stocks from the others, and additional dams- Xiluodu Dam (begun in 2005) and Xiangjiaba Dam (begun in 2006)- being constructed in the lower reaches of Jinsha River (Fig. 1) will likely completely break up the main spawning fields. This may pose a serious threat to the survival of largemouth bronze gudgeon in the Yangtze River. Our findings provide a good starting point to study the effect of man-made interventions like dams to the fragile ecosystem of fishes in our rivers and the conservation of and further research on the largemouth bronze gudgeon fish in the future.

We thank Taiming Yan, Zhonghua Duan, Shengguo Dan, Zhiguo Miao, Xin Gao and so many fisher folks and local govern- 
ment fishery supervisors for their kind help in largemouth bronze gudgeon sampling. This work was supported by joint funds of the National Natural Science Foundation of China and Yalong River Hydropower Development Foundation (50679095), and grants from Research Programs of the Executive Office of the State Council Three Gorges Project construction committee (SX2007-019) and China Yangtze Three Gorges Project Development Corporation (0714086), and non-profit industry financial program of MWR of China (200901011).

\section{REFERENCES}

Aljanabi, S. M., and Martinez, I. (1997) Universal and rapid salt-extraction of high quality genomic DNA for PCR-based techniques. Nucleic Acids Res. 25, 4692-4693.

Behnke, R. J. (1972) The systematics of salmonid fishes of recently glaciated lakes. J. Fish. Res. Board Can. 29, 639-671.

Chen, D., Duan, X., Liu, S., Shi, W., and Wang, B. (2002) On the dynamics of fishery resources of the Yangtze River and its management. Acta Hydrobiologia Sinica 26, 685-690 (In Chinese with English Abstract).

Cornuet, J. M., and Luikart, G. (1996) Description and power analysis of two tests for detecting recent population bottlenecks from allele frequency data. Genetics 144, 20012014.

Deiner, K., Garza, J. C., Coey, R., and Girman, D. J. (2007) Population structure and genetic diversity of trout (Oncorhynchus mykiss) above and below natural and manmade barriers in the Russian River, California. Conserv. Genet. 8, 437-454.

DeWoody, J. A., and Avise, J. C. (2000) Microsatellite variation in marine, freshwater and anadromous fishes compared with other animals. J. Fish Biol. 56, 461-473.

Duan, X., Chen, D., Liu, S., Chi, C., and Yang, R. (2002) Studies on status of fishery resources in Three Gorges reservoir reaches of the Yangtze River. Acta Hydrobiologia Sinica 26, 605-611 (In Chinese with English Abstract).

Excoffier, L., Laval, G., and Schneider, S. (2005) Arlequin ver. 3.0: An integrated software package for population genetics data analysis. Evol. Bioinform. Online 1, 47-50.

Fu, C., Wu, J., Chen, J., Wu, Q., and Lei, G. (2003) Freshwater fish biodiversity in the Yangtze River basin of China: patterns, threats and conservation. Biodivers. Conserv. 12, 1649-1685.

Gaggiotti, O. E., Lange, O., Rassmann, K., and Glidden, C. (1999) A comparison of two indirect methods for estimating gene flow using microsatellite data. Mol. Ecol. 8, 15131520 .

Goudet, J. (2001) FSTAT, a program to estimate and test gene diversities and fixation indices (version 2.9.3).

Hildebrand, R. H. (2003) The roles of carrying capacity, immigration and population synchrony on persistence of stream resident cutthroat trout. Biol. Conserv. 110, 257-266.

Hutchinson, D. W., and Templeton, A. R. (1999) Correlation of pairwise genetic and geographic distance measures: inferring the relative influences of gene flow and drift on the distribution of genetic variability. Evolution 53, 1898-1914.

Institute of Hydrobiology, Hubei Province (1976) Fishes of the Yangtze River (In Chinese). The Scientific Press, Beijing.

Liao, X., Zhu, B., Yu, X., Tan, D., Chang, J., and Tong, J. (2006) Isolation and characterization of polymorphic microsatellites in a Yangtze River fish, brass gudgeon (Coreius heterodon Bleeker). Mol. Ecol. Notes 6, 393-395.

Liao, X., Yu, X., Chang, J., and Tong, J. (2007) Polymorphic microsatellites in largemouth bronze gudgeon (Coreius guichenoti) developed from repeat-enriched libraries and cross-species amplifications. Mol. Ecol. Notes 7, 1104-1107.

Lippe, C., Dumont, P., and Bernatchez, L. (2006) High genetic diversity and no inbreeding in the endangered copper redhorse, Moxostoma hubbsi (Catostomidae, Pisces): the positive sides of a long generation time. Mol. Ecol. 15, 17691780 .

Liu, L., Wu, G., and Wang, Z. (1990) Reproduction ecology of Coreius Heterodon (Bleeker) and Coreius Guichenoti (Sauvage et Dabry) in the mainstream of the Changjiang River after the construction of Gezhouba Dam. Acta Hydrobiologia Sinica 14, 205-215 (In Chinese with English Abstract).

Meldgaard, T., Nielson, E. E., and Loeschcke, V. (2003) Fragmentation by weirs in a riverine system: a study of genetic variation in time and space among populations of European grayling (Thymallus thymallus) in a Danish river system. Conserv. Genet. 4, 735-747.

Panaud, O., Chen, X., and McCouch, S. R. (1996) Development of microsatellite markers and characterization of simple sequence length polymorphism (SSLP) in rice (Oryza sativa L.). Mol. Gen. Genet. 252, 597-607.

Park, Y. S., Chang, J., Lek, S., Cao, W., and Brosse, S. (2004) Conservation strategies for endemic fish species threatened by the Three Gorges Dam. Conserv. Biol. 17, 1748-1758.

Reid, S. M., Wilson, C. C., Mandrak, N. E., and Carl, L. M. (2008) Population structure and genetic diversity of black redhorse (Moxostoma duquesnei) in a highly fragmented watershed. Conserv. Genet. 9, 531-546.

Rice, W. R. (1989) Analyzing tables of statistical tests. Evolution 43, 223-225.

The Changjiang River fisheries investigation team of Sichuan Province. (1979) Investigation reports on two kinds of gudgeons in Sichuan. Sichuan Fish. S, 1-22 (In Chinese).

Van Oosterhout, C., Hutchinson, W. F., Wills, D. P. M., and Shipley, P. (2004) MICRO-CHECKER: software for identifying and correcting genotyping errors in microsatellite data. Mol. Ecol. Notes 4, 535-538.

Whitehead, A., Anderson, S. L., Kuivila, K. M., Roach, J. L., and May, B. (2003) Genetic variation among interconnected populations of Catostomus occidentalis: implications for distinguishing impacts of contaminants from biogeographic structuring. Mol. Ecol. 12, 2817-2833.

Xu, S., Zhang, Y., Wang, D., Li, Z., and Chen, D. (2007) Genetic diversity in largemouth bronze gudgeon (Coreius guichenoti Sauvage et Dabry) from Yibin section of Yangtze River based on sequence of microsatellite DNA. Freshwater Fish. 3, 76-79 (In Chinese with English Abstract).

Yamamoto, S., Morita, K., Koizumi, I., and Maekawa, K. (2004) Genetic differentiation of white-spotted charr (Salvelinus leucomaenis) populations after habitat fragmentation: spatial-temporal changes in gene frequencies. Conserv. Genet. 5, 529-538.

Yeh, F. C., Yang, R. C., Boyle, T. B. J., Ye, Z. H., and Mao, J. X. (1997) POPGENE, the user-friendly shareware for population genetic analysis. Molecular Biology and Biotechnology Centre, University of Alberta, Canada.

Yu, X., Luo, T., and Zhou, H. (2005) Large-scale patterns in species diversity of fishes in the Yangtze River Basin. Chinese Biodiver. 13, 473-495 (In Chinese with English Abstract).

Yuan, X., Yan, L., Xu, S., Wang, D., Zhang, Y., and Chen, D. (2008) Genetic diversity of bronze gudgeon (Coreius heterodon) and largemouth bronze gudgeon (C. guichenoti) in Yangtze River Basin. J. Fish. Sci. China 15, 377-385 (In Chinese with English Abstract). 